\title{
FORECASTING HOUSE PRICES IN TURKEY: GLM, VAR AND TIME SERIES APPROACHES
}

\author{
DOI: 10.17261/Pressacademia.2020.1310 \\ JBEF- V.9-ISS.4-2020(1)-p.274-291
}

\section{Bilgi Yilmaz ${ }^{1}$, A.Sevtap Selcuk Kestel ${ }^{2}$}

${ }^{1}$ Technische Universitat Kaiserslautern, Department of Mathematics, TU Kaiserslautern Gottlieb-Daimler-Straße 47, Kaiserslautern, Germany. Bilgivilmaz07@gmail.com, ORCID: 0000-0002-9646-2757

${ }^{2}$ Middle East Technical University, Institute of Applied Mathematics, Cankaya, Ankara, Turkey. skestel@metu.edu.tr, ORCID: 0000-0001-5647-7973

Date Received: September 30, 2020

Date Accepted: December 10, 2020

To cite this document

Yilmaz, B., Kestel, A.S.S., (2020). Forecasting house prices in Turkey: GLM, VAR and time series approaches. Journal of Business, Economics and Finance (JBEF), V.9(4), p.274-291.

Permanent link to this document: http://doi.org/10.17261/Pressacademia.2020.1310

Copyright: Published by PressAcademia and limited licensed re-use rights only.

\section{ABSTRACT}

Purpose- A wide range of decision-makers is interested in educated forecasts for house prices. The technical analysis introduced in this study aims to estimate future (forecasted) house prices and provide sufficient evidence in support of the adequacy of the estimated models obtained from parametric and non-parametric modeling methods for Turkey's housing market.

Methodology- We employ non-parametric and various time series methods to find appropriate fits to forecast Turkey's house price index (HPI). In our modelling, we consider macroeconomic indicators related to housing markets, such as; gold, interest rate and currencies. In this study, first using the explanatory variables, we construct two Generalized Linear Models (GLM) and a Vector Auto Regressive (VAR) model. Then, we construct two univariate time series models. HPI series inherits seasonality. Even though the HPI contains seasonality, first, we neglect the seasonal effect and come up an Autoregressive Moving Average $(A R M A(p, q))$ model among many other alternative ARMA models. Second, we consider the seasonality effect on the housing market index and construct a seasonal Autoregressive Integrated Moving Average $(A R I M A(p, d, q)(P, D, Q))$ and exponential smoothing models.

Findings- The analysis identifies forecasts of Turkey's housing market index from both the seasonal $A R I M A(p, d, q)(P, D, Q)_{m}$ and Holt Winter models as accurate models compared to classical time series models, namely $\operatorname{ARIMA}(p, d, q)$ models, based on the explanation power measure $\left(R^{\wedge} 2\right)$ values and out-of-sample error measures MSE, RMSE and MAE.

Conclusion- The study has three main contributions: i) Our forecast shows Turkey's housing market's return will not increase in the following 12months. ii) The seasonal ARIMA and exponential smoothing models forecast some negative returns within the given forecasting period, which should be considered a warning for Turkey's housing market for the future. iii) GLM and VAR models illustrate that Turkey's housing market shows a high dependence on gold, inflation, and foreign exchange rates than other well-known economic indicators.

Keywords: Turkey's housing market, GLM, time series, forecasting, VAR.

JEL Codes: R32, C22, C15

\section{INTRODUCTION}

Analyses on house price behavior and its forecasting is a critical attempt to policymakers, investors, and individual buyers and sellers in Turkey for many reasons. To begin with, housing represents not only a substantial aggregate portion of households' wealth but also it carries out an essential part of the entire economy. Hence, Turkey's housing market directly attached to its' national economy through households' expenditures on housing and expenses related to housing. Consequently, house prices possess the potential to widely affect household consumption through the ability of housing financing-related debts. Therefore, price fluctuations in Turkey's housing market are of great concern to policymakers and market participants, and also, they have devastating implications on its' national economy. 
Over the last two decades, house prices have increased regularly due to the global capital flow to Turkey's economy. Figure 1 illustrates nationwide Turkey's nominal house price evolution for all types of housing for the period from January-2010 to May2019. In this period, overall house prices have increased by $143 \%$ in Turkey. This consecutive increase is uninterrupted even by the 2008 global economic disturbance, which is caused by the US housing market collapse.

Figure 1 also shows that even though house prices are decreased a little bit in early 2019, they start to increase in 2019 again. However, such an increase is not due to Turkey's housing market recovery. There are three fundamental reasons behind the increase: i) the severe tax and duty burden increase, ii) the dramatic increase in currencies, iii) the decrease in mortgage loans, and the consumers' desire to purchase a house based on the cultural reasons.

Figure 1: Monthly House Price Evolution in Turkey (2010:1-2019:5)

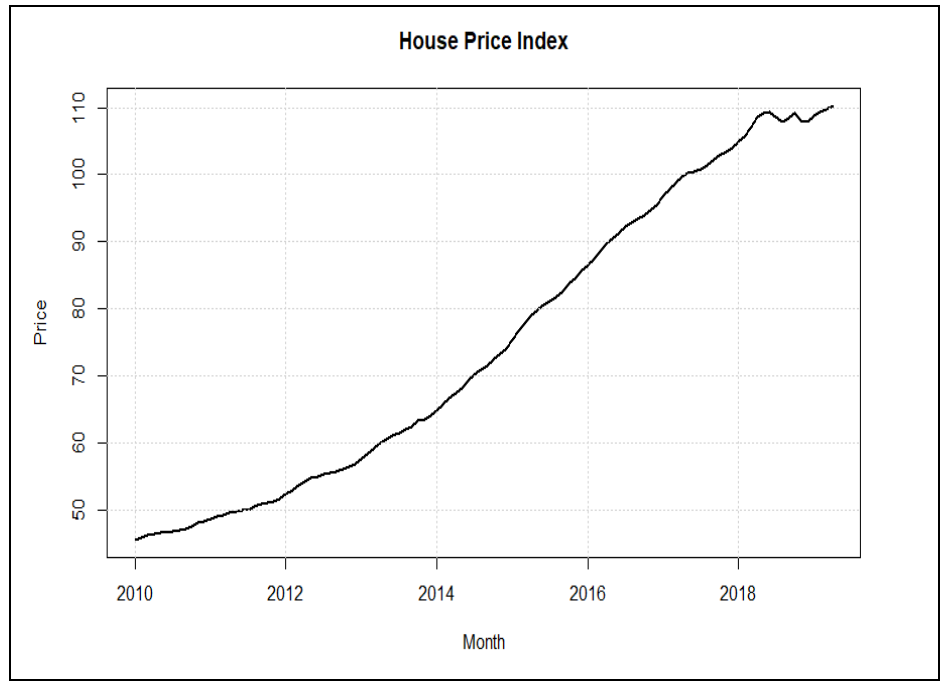

Starting from early 2000, there has been an accelerating interest in Turkey's housing market; thanks to the growth in national economy and political regulations on the economy and housing market. The literature on forecasting house prices is no different, although the majority of studies seem to focus on multivariate forecasting methods. In Turkey, many researchers have long tried to identify underlying drivers of house prices and use the price drivers to estimate house prices. To this end, an increased number of researches has focuses on house price dynamics and explore them by employing hedonic method (see Yayar and Gül, 2014; Öztürk and Fitöz, 2012; Yayar and Karaca, 2014), which uses some market-specific factors and common factors such as inflation, income, housing statistics, and demographics. Hedonic method is the most frequently used modelling approach to identify house price dynamics in Turkey.

Although the number of researches has been limited, artificial neural networks are also showing considerable potential in the field of house price prediction in Turkey (Selim, 2009; Dombaycı, 2010). On the contrary to hedonic, classical multiple regression and artificial neural networks methods, univariate time series models have been found to forecast very well over shorter periods by Crawford and Frantantoni (2003). It is because short-term factors are expected to have a slow change (Tse, 1997).

Especially, autoregressive integrated moving average (ARIMA) models have received extraordinary attention from researchers to predict and forecast house prices in many housing markets. For instance, Tse (1997) examines forecasting of house prices in Hong Kong housing market by adopting ARIMA to capture the short-term house price behavior showing that integrated models perform better than other time series model classes. In a similar study, Crawford and Frantantoni (2003), compare ARIMA models to generalized autoregressive conditional heteroskedastic (GARCH) and regime-switching models and discover that simple ARIMA models generally perform better when comparing out-of-sample forecast accuracy, while the regime-switching model performs better in-sample. Chin and Fan (2005) compare three distinct ARIMA models in an application on residential house prices in Singapore housing market. They observe an ARIMA model that contains dummy variables performs better than an ARIMA model 
with ARCH errors, but only marginally better than the original model. By considering a similar argument, Hepşen and Vatansever (2011) use a standard Box-Jenkins ARIMA modelling approach to forecast house price trends in Dubai housing market.

Nevertheless, everyone is not as enthusiastic about the forecasting strength of ARIMA models. For instance, Stevenson (2007) notifies that although ARIMA models are capable in predicting broad market trends, these models differ substantially in their forecasts obtained from various model specifications since they are sensitive to model preference biases.

There is a considerable amount of literature which attempts to determine house price dynamics in Turkey, but limited number of studies focus on the prediction of house prices. Unlike modelling house price dynamics, forecasting house prices have received limited attention and none of these focus on the univariate time series modelling, Vector autoregressive (VAR) and Generalize Linear Modelling (GLM) approaches to our best knowledge. Note also that while there are studies that using VAR to predict house prices in the literature (e.g. Hui and Yue, 2006), there is only Yilmaz (2019) contains application of GLM for housing market which analyze the US housing market. Hence, this study is the first attempt to analyze the forecastability of house prices by using univariate times series, VAR and GLM approaches in Turkey's housing market.

The objective of the study is to guide the reader to better comprehend the nature of Turkey's housing market concerning its price movement through a robust analysis of time series, exponential smoothing, VAR, and GLM methods. The analysis culminates in the development of models constructed to forecast house prices in Turkey. The major contribution of the study is to provide a critically notified analysis of the housing market and the forecastability of house prices in Turkey.

To support our argument, initially, we present an extensive literature review on the VAR, GLM, and univariate time series analysis applications to housing markets in the world and Turkey. Subsequently, we determine the related explanatory variables for VAR and GLM models and determine VAR, GLM, ARMA, seasonal ARIMA, and exponential smoothing models that best represent the log-return house price series of Turkey. Then, we made some forecasts following selected three models, among many alternatives.

All of the models accommodate to track the direction of changes in house prices. Further, the Granger causality test determines the causality of the selected explanatory variables. Additionally, GLM and VAR models identify the macroeconomic drivers of Turkey's housing market. VAR catch inflation and past values of HPI as the explanatory variables, while GLM picks gold and USD as significant explanatory variables for HPI.

The most significant practicality of the study is to suggest a way to determine the cyclical turning points in Turkey's house price series. Also, in practice, these modelling approaches are not only employed to identify the cyclical patterns and cyclical turning points of economic data sets but also to analyze the efficiency of the housing market (Tse, 1997; Gatzlaff and Tirtiroglu, 1995). Therefore, our study is expected also to lead the analysis of efficiency of Turkey's housing market.

The organization of the study is as follows. In Section 2, we summarize the previous studies that consider the time series analysis for housing markets. The formulations for the GLM, VAR, univariate time series and exponential smoothing methods are given in Section 3 and kept brief without any proof. Section 4 reviews Turkey's house price index properties and its initial analysis. Then, we introduce the best selected models chosen whose details are presented in Appendixes along with their prediction and forecasting powers in Section 5. This section also discusses models' prediction, accuracy, forecasting, and forecasting confidence intervals for the selected models. Finally, we conclude the study in Section 6.

\section{RELATED STUDIES}

McGough and Tsolacos (1995) utilize ARIMA models for the short-term forecasting of rental values of three commercial property sectors in the UK real estate market. The findings in this study reveal that retail, office and industrial rents are admirably fitted by $\operatorname{ARIMA}(1,2,0), \operatorname{ARIMA}(0,2,1)$ and $\operatorname{ARIMA}(3,2,0)$ models in the UK, respectively. These models suggest that for retail and industrial rents, the past changes affect their current and future changes, while for office rents, their present and future changes are influenced by past shocks. Their findings provide a greater comprehension of the short-term dynamics of commercial rental values and the forecasting of turning points.

In a similar study, Tse (1997) develops ARIMA models to predict the office and industrial property prices in Hong Kong real estate market. This study compares the forecasting performance of ARIMA models for the two property sectors. In particular, Tse applies the proportion of the RMSE of the model forecasts to the mean value to identify cyclical turning points. Whenever the reversed change in house prices is larger than the proportion value, a turning point is anticipated to occur. However, his findings also show that the ARIMA analysis is inadequate at identifying market turning points for the longer term. 
Crawford and Frantantoni (2003) accurately compares both in-sample and out-of-sample forecasting performance of three univariate time series models for house price forecasting of the US housing market. More precisely, they meaningfully compare an ARIMA model, a GARCH model and finally, a regime-switching model. It is unusual to note, however, that their findings show that the simple ARIMA model performs better in tests of out-of-sample forecastability, while the regime-switching model performs better in-sample.

Guirguis et al. (2005) present an impressive critique of house price forecasting methods. They point out that many previous studies, which attempt to forecast house prices had relied on forecasts that employ the use of constant coefficients and do not account for the sub-sample instability of house prices. To consider this instability, Guirguis et al. employ six empirical models using a rolling vector error correction model (VECM); a rolling autoregressive representation (RAR); a rolling generalized autoregressive conditional heteroskedastic (GARCH) model; a Kalman filter with a random walk (KRW); a Kalman filter with an autoregressive time variation (KAR) and finally; an Exponential smoothing with trend and seasonality (ES) model.

Partially motivated by Crawford and Frantantoni (2003), Miles (2008) come up some non-linear forecasting models including a threshold autoregression (TAR), a bilinear (BL) and a generalized autoregressive (GAR) models. After some deliberation, Miles eventually adopts a GAR model for house prices in the study since it is easily estimated by employing the ordinary least squares, and he improves forecasting power of the models for the same US states that are analyzed by Crawford and Frantantoni (2003). Miles (2008) then compares the forecasting performance to the best ARMA and GARCH forecasting models and observes GAR model produces superior out-of-sample forecasts than both the simple ARMA and GARCH models, particularly in housing markets which exposed high levels of house price volatility.

Later, Rapach and Strauss (2009) accomplish similar outcomes as outcomes of Miles (2008). Their analyses on state-level house price growth in the US housing market between 1995-2006 and comparison an autoregressive benchmark model with others including some auxiliary economic explanatory variables recommend that autoregressive model, as well as models that make use of additional economic explanatory variables, tend to provide fairly reliable forecasts for house prices. However, the accuracy of their forecasts is broadly dependent upon the strength of growth in house prices over the investigated period. More precisely, they observe that house price forecasts for the states that exhibited relatively moderate house price growth are often considerably more accurate than forecasts for states, which exhibited strong house price growth over the investigated period. The authors also suggest that the fact house price forecasts for states, which exhibits the strongest price growth are inaccurate may potentially indicate that house prices in these states are plausibly significantly out of line with economic fundamentals.

Gao et al. (2009) also addresses the issue of house price forecast performance variability across several US sub-housing markets over two large panel data of the US regional housing markets. They use the empirical evidence recommending house price exhibits a mean reversion and serial correlation to employ an autoregressive mean reversion (ARMR) model to forecast house prices. As expected, their result displays forecasting of house prices for markets which display a high level of volatility in house prices tend to result in AR coefficients, which are generally considerably larger than those found in forecasts of less volatile housing markets. Also, they discover house price forecasting for prices in uptrend periods have significantly larger AR coefficients than those made in downtrend periods. Eventual, they suggest it as evidence of downtrend period rigidity in the housing market.

\section{METHOD}

There are three modelling approaches in this study. First, we use a Generalized Linear Model (GLM) to determine how well the mathematical models that based on flexible generalization of ordinary linear regression captures the housing market behavior in Turkey. Second, we use a Vector Autoregressive (VAR) approach to analyze the joint behavior of important related variables on the house prices. Third, we employ univariate time series approach, which studies the within-dynamics in the price index itself.

In the GLM modelling, we follow the structure proposed by Nelder and Baker (1972) closely. Also, for VAR modelling approach Ooms (2012) offers detailed descriptions. The general model specifications for time series analysis we made in this study are similar to those outlined by Crawford and Fantantoni (2003). These models are theoretical in the sense that they are nonstructural. The models simply make use of the lagged value of the dependent variable, lagged values of the error terms, and in some cases, lagged variances as well. All of the models considered in the context of the study are ubiquitous among the forecasting literature and have been employed with high degrees of success in a variety of fields. Additionally, Shumway and Stoffer (2010) is followed for the theoretical background of the univariate time series analysis. 


\subsection{Generalized Linear Models}

Given a random variable vector $Y=\left(Y_{1}, Y_{2}, \ldots, Y_{N}\right)$ having a mean vector $\mu$ and an explanatory variable matrix $X$ of order $N \times p$ and a p-dimensional parameter vector $\beta$, GLM have the primary objective to investigate the link between $\mu$ and $X$ through vector $\beta$. Here, $\mu$ represents the systematic part of the model. It may be written as the existence of covariate $x_{1}, x_{2}, \ldots, x_{p}$ and $\beta_{j}$ where $j=1,2, \ldots, p$ as

$$
\mu_{i}=\sum_{j=1}^{p} \beta_{j} x_{i j}, i=1,2, \ldots, N .
$$

Here, $x_{i j}$ represents the value of observation i's jth covariance. In this setting $\gamma$ is normally distributed and covariates $x_{1}, x_{2}, \ldots, x_{p}$ produce a linear map denoted as $\eta_{i}=\sum_{j=1}^{p} \beta_{j} x_{i j}$. Here, the relation among the systematic and the random components is $\eta=\mu$. Note that $\eta$ and $\mu$ are identical. So, it can be expressed by the help of a link function $g$, as $\eta_{i}=g\left(\mu_{i}\right)$.

\subsection{Vector Autoregressive Models}

In this approach the vector time-series $x[n]$ is modelled as an auto regressive (AR) process given as

$$
x[n]=-\sum_{i=1}^{p} A[i] x[n-i]+u[n],
$$

where $u[n]$ represents a multivariate white noise, with a cross-covariance matrix denoted with $\operatorname{Var}(u[n])=\Sigma$, if $k=0$, otherwise $\operatorname{Var}(u[n])=0$. Here, $A[i]$ are called AR coefficients since they regress $x[n]$ onto its own past values. In this setting, $p$ is called the order of the auto-regression and it refers to the above model, with adjustable parameters $A[i]$ and $\Sigma$ to be estimated, as a $\operatorname{VAR}(p)$ model.

There are two critical interpretations of this modelling approach: $\mathrm{i})$, it can be considered to model $x[n]$ as the output of a multivariate linear filter driven by the Brownian motion input $u[n]$. Such a filter has a rational transfer function that containing $A[i]$ in the denominator matrix polynomial. The interpretation makes clear that the model captures the temporal structure of $x[n]$ since $u[n]$ has no (linear) temporal structure by its definition. All temporal structure present in $x[n]$ must be included in $A[i]$. ii) VAR model can be considered as a linear prediction model, which predicts the current value of $x[n]$ based on a linear combination of the most recent lag values $p$. Consequently, the current value of a component $x_{i}[n]$ is predicted using a linear combination of its own and the other components past values. Here, the second interpretation illustrates its value in quantifying Granger causality between (groups of) components.

\subsection{ARIMA models}

Univariate time series analysis is based on the straight modelling of the lagged relationships among a data series and its past. An autoregressive component (AR) indicating the number of lags of the dependent variable that is to be included, and a moving average (MA) component that captures the effect of lagged values of the error term form an ARMA process.

An $\operatorname{ARMA}(p, q)$ process is represented by

$$
y_{t}=\theta_{0}+\phi_{1} y_{t-1}+\cdots+\phi_{p} y_{t-p}+\epsilon_{t}-\theta_{1} \epsilon_{t-1}-\cdots-\theta_{q} \epsilon_{t-q} .
$$

This formula can be rearranged by using the lag operator $D$ as follows

$$
\phi(D) y_{t}=\theta(D) \epsilon_{t} .
$$

Here, $\phi(z)$ and $\theta(z)$ are polynomials of orders $p$ and $q$ in $z$, respectively, and $\epsilon_{t}$ is a purely random process with mean zero and variance $\sigma_{\epsilon}^{2}$.

In practical applications, especially, most of the economic data series are non-stationary. Therefore, it is essential to remove nonstationary sources from the data by differencing the data as many as it gets into stationary form. Thus, the series can be represented by an autoregressive integrated moving average process of orders, $p, d, q$, or an $A R I M A(p, d, q)$ process. ARIMA models do not consider any particular pattern in the observed data series to be forecasted. Here, the integrated (I) part refers to the degree of differencing $(d)$. The Box-Jenkins method has a three-stage approach for identifying, estimating and verifying the 
ARIMA models. The family of ARIMA processes provides a distinct set of models that capable of representing economic data series that may not be stationary, but are homogeneous and in statistical equilibrium (Box et al., 1994). The Box-Jenkins approach to time-series model building is a method to determine if an ARIMA model adequately represents the data-generating process.

The general $\operatorname{ARIMA}(p, d, q)$ process is of the form:

$$
\Delta^{d} y_{t}=\theta_{0}+\phi_{1} \Delta^{d} y_{t-1}+\cdots+\phi_{p} \Delta^{d} y_{t-p}+\epsilon_{t}-\theta_{1} \epsilon_{t-1}-\cdots-\theta_{q} \epsilon_{t-q},
$$

where $\Delta y_{t}=y_{t}-y_{t-1}=(1-D) y_{t}$. This may be compactly rewritten as

$$
\phi(D) \Delta^{d} y_{t}=\theta_{0}+\theta(D) \epsilon_{t}
$$

Here, $\phi(D)$, autoregressive operator, and $\theta(D)$, moving average operator, are the polynomials lag operator and $\Delta^{d} y_{t}=$ $(1-D)^{d} y_{t}$ is the $d^{\text {th }}$ difference of $y_{t}$.

\subsection{Seasonal ARIMA Models}

In the previous subsection, we have restricted the focus to non-seasonal ARIMA models. However, in real life applications the dependence on the past tends to occur strongly at some underlying seasonal lag. The modified ARIMA models are capable of modelling a wide range of seasonal effect. A seasonal ARIMA model is classified by including additional seasonal parameters into the classical ARIMA models we introduce in the previous subsection. The seasonal ARIMA model represented with the following formula

$$
\operatorname{ARIMA}(\boldsymbol{p}, \boldsymbol{d}, q)(P, D, Q)_{m}
$$

We use the uppercase notation for the seasonal parts of the model, and lowercase notation for the non-seasonal parts of the model. Here, $P, D, Q$ and $m$ denote the number of seasonal autoregressive (SAR) terms, seasonal differences, seasonal moving average (SMA) terms, and observations per year, respectively.

\subsection{Exponential Smoothing}

The use of exponential smoothing in automatic forecasting (Brown, 1959; Gardner Jr, 1985; Hyndman et al., 2002) includes a variety of methods such as the simple exponential smoothing method, Holt's linear method, additive Holt-Winters method, and multiplicative Holt-Winters' method, etc. In this paper, we employ additive Holt-Winters method (Winters, 1960; Holt, 2004)) which is widely used to forecast time series that contains seasonality and it is given as

$$
\hat{y}_{(t+h \mid t)}=l_{t}+h b_{t}+s_{t+h-m(k+1)} \text {. }
$$

In this model the level, $l_{t}$, is defined as

$$
l_{t}=\alpha\left(y_{t}-s_{t-m}\right)+(1-\alpha)\left(l_{t-1}-b_{t-1}\right),
$$

whereas, the trend, $b_{t}$, is

$$
b_{t}=\beta\left(l_{t}-l_{t-1}\right)+(1-\beta) b_{t-1}
$$

and the seasonal component, $s_{t}$, is

$$
s_{t}=\gamma\left(y_{t}-l_{t-1}-b_{t-1}\right)+(1-\gamma) s_{t-m}
$$

where the parameter $k$ is the integer part of $(h-1 / m)$. Here, $k$ guarantees that the estimates of the seasonal indices used in forecasting related to the final year of the observation. The level equation gives a weighted average among the seasonally adjusted observation $y_{t}-s_{t-m}$ and non-seasonal forecast $l_{t-1}+b_{t-1}$ at time $t$. The trend equation is identical to the classical Holt's linear method. The seasonal equation presents a weighted average between the current seasonal index, $\left(y_{t}-l_{t-1}-b_{t-1}\right)$, and the seasonal index of the same season in the previous year. Here, $\alpha$ denotes the level component, $\beta$ denotes the trend component, and $\gamma$ denotes the seasonality component. 


\section{HOUSE PRICES AND THE RELATED VARIABLES}

Government agencies publish various indices such as house price index, index of private housing rental prices, New Privately Owned Housing index, mortgage rate, on housing markets to design urban planning and national economic policies, and various studies aim to predict future movements based on historical indices. Among those indices the house price indices are appraised as a very valuable indicator for judging housing markets behavior accurately. These indices are basically the compilation of every possible factors which may have an influence on the house price, such as city, size, type, location, use etc. Additionally, real estate as a commodity has an influential effect on the economies, though transactions are extremely infrequent.

Perhaps the most transparent housing index for Turkey's housing market is the sales price index (HPI) provided by the Central Bank of the Republic Turkey (TCMB) which is chosen for carrying out the analyses on Turkey's housing market price evaluation. The HPI is a major tool for professionals, researchers, and policymakers to track down the general price movements and trends in Turkey's housing market. The monthly HPI values between January 2010 and May 2019 are retrieved from the online portal of TCBM, yielding adequate number of observations (113) for the analyses.

We use a variety of econometric variables, such as commodity (gold), financial indicators (USD, Euro, mortgage rate), macroeconomic indicators (unemployment, inflation, cost of living index, economic confidence index), to predict HPI values. Table 1 presents their abbreviations and the summary statistics of these variables. USD/TL and EURO/TL currencies are chosen since Turkey's economy highly relies on imports. As commodity gold prices is one of the most influential investment tools in Turkey. In many studies, it is proven that inflation and real estate markets are highly dependent on each other and investing in the real estate market may protect the capital against inflation (Yilmaz, 2019; Yilmaz and Selcuk-Kestel, 2019). Therefore, we take into account inflation and fixed-rate mortgage (FRM) since house prices require most buyers to finance through loan. On the other hand, to show the economic power of the community and to analyze the impact of trust in the economy, we consider the cost of living index (COSTL) and economic confidence index (ECONOMICCI). As in fully commutative markets, housing markets are also highly affected by the income of the community, which is rated by unemployment rate that has an influence on the markets. Here, it is worth to emphasize that the summary statistics expose the transformed data since the series are not stationary in their original form. Augmented Dickey-Fuller (ADF) -tests on the transformed variables justify that the series are stationary ( $<<0.05$; Table 2).

Table 1: The Summary of Descriptive Statistics

\begin{tabular}{llllll}
\hline Variable & Abrv. & Max & Min & Mean & Std.Dev \\
\hline GOLD & GOLD & 0.086 & -0.036 & 0.006 & 0.018 \\
\hline USD & USD & 0.082 & -0.038 & 0.005 & 0.015 \\
\hline EURO & EURO & 0.076 & -0.043 & 0.004 & 0.015 \\
\hline INFLATION & INF & 0.027 & -0.006 & 0.003 & 0.004 \\
\hline FRM & FRM & 0.289 & 0.083 & 0.132 & 0.040 \\
\hline COSTL & CTL & 0.107 & -0.252 & 0.0004 & 0.046 \\
\hline ECONOMICCI & ECI & 0.031 & -0.045 & -0.0004 & 0.012 \\
\hline UNEMPLOYMENT & UE & 0.147 & 0.073 & 0.103 & 0.016 \\
\hline HPI & HPI & 0.008 & -0.005 & 0.003 & 0.002 \\
\hline
\end{tabular}

Table 2: Stationarity of Variables (ADF-Test)

\begin{tabular}{ll}
\hline & Dickey-Fuller \\
\hline GOLD & $-4.507^{*}$ \\
\hline USD & $-5.7478^{*}$ \\
\hline EURO & $-5.3233^{*}$ \\
\hline INFLATION & $-5.1387^{*}$ \\
\hline FRM & $-4.3148^{*}$ \\
\hline
\end{tabular}




\begin{tabular}{ll}
\hline COSTL & $-4.7555^{*}$ \\
\hline ECONOMICCI & $-4.4213^{*}$ \\
\hline UNEMPLOYMENT & $-4.6518^{*}$ \\
\hline $\mathrm{HPI}$ & $-3.4549^{* *}$ \\
\hline${ }^{*} \mathrm{p}<0.01 ;{ }^{*} \mathrm{p}<0.05$ & \\
\hline
\end{tabular}

The variables chosen pose strong association among each other. Table 3 illustrates that the highest correlation is between currencies (83\%), which is followed by between GOLD and USD (64\%) and EURO (60\%). The remaining associations are relatively small. The lowest correlation is observed between GOLD and UE (2\%). On the other hand, while the dependent variable has the highest and lowest correlation with FRM (-30\%) and CTL $(-0.3 \%)$ yielding a negative dependence to these and all others except $\mathrm{ECl}$. Such a result is expected since the community prefers to invest in alternative products while they are becoming more valuable. This result might also express as the population prefers to invest in liquid assets rather than illiquid assets. Additionally, the correlation between HPI and unemployment reveals that when the number of unemployment increases, house prices are affected negatively, which might be considered as the effect of a decrease in housing demand. Also consistent with the literature, the correlation coefficients show that house prices are negatively correlated with mortgage rate $(-30 \%)$. Interestingly, on the contrary to common belief, the house prices are negatively correlated with inflation (-30\%) in Turkey.

Table 3: Correlation Matrix

\begin{tabular}{|c|c|c|c|c|c|c|c|c|}
\hline & GOLD & USD & EURO & INF & FRM & CTL & $\mathrm{ECl}$ & UE \\
\hline USD & 0.66 & 1 & & & & & & \\
\hline EURO & 0.59 & 0.83 & 1 & & & & & \\
\hline INF & 0.17 & 0.35 & 0.38 & 1 & & & & \\
\hline FRM & 0.11 & 0.17 & 0.24 & 0.30 & 1 & & & \\
\hline CTL & 0.19 & 0.24 & 0.17 & 0.37 & 0.18 & 1 & & \\
\hline $\mathrm{ECl}$ & -0.30 & -0.48 & -0.49 & -0.40 & -0.39 & -0.31 & 1 & \\
\hline UE & 0.02 & 0.06 & 0.08 & -0.03 & 0.05 & 0.03 & -0.16 & 1 \\
\hline $\mathrm{HPI}$ & -0.25 & -0.19 & -0.32 & -0.15 & -0.29 & -0.03 & 0.18 & -0.28 \\
\hline
\end{tabular}

It is well known that the correlations may not be strong enough to show the direction of influence even they are very high. Therefore, we employ the Granger causality tests to capture the direction of the causality between variables. Table 4 illustrates the outcomes of Granger causalities which expose two important facts about the data set: i) Unemployment rate and cost of living do not have causal influence on house prices. Furthermore, even though these series have correlations, house prices are not causing these two variables either, ii) On the contrary to other common believes in the literature, the fixed rate mortgage rate does not cause $\mathrm{HPI}$, however, house prices cause fixed rate mortgage. In this respect, we may conclude that the mortgage rate is used to adjust house prices and hence it is determined according to house prices in the market. Therefore, we include the high impact variables except FRM, and employment rate and cost of living variables.

\section{Table 4: Granger Causality (GC) Tests}

\begin{tabular}{|l|c|c|c|}
\hline Hypothesis & F-Stat & p-value & Causality Direction \\
\hline HPI do not GC GOLD & 0.575 & 0.6810 & GOLD $\rightarrow$ HPI \\
GOLD do not GC HPI & 4.459 & $0.0018^{*}$ & \\
\hline HPI do not GC USD & 0.643 & 0.5883 & USD $\rightarrow$ HPI \\
USD do not GC HPI & 4.022 & $0.0082^{*}$ & \\
\hline HPI do not GC EURO & 0.823 & 0.4824 & EURO $\rightarrow$ HPI \\
EURO do not GC HPI & 3.206 & $0.0241^{*}$ & \\
\hline HPI do not GC INF & 1.566 & 0.1068 & INF $\rightarrow$ HPI \\
INF do not GC HPI & 2.407 & $0.0069^{*}$ & HPI $\rightarrow$ FRM \\
\hline HPI do not GC FRM & 3.742 & $5.4 \mathrm{E}-05^{*}$ & \\
FRM do not GC HPI & 1.279 & 0.2355 & \\
\hline
\end{tabular}




\begin{tabular}{|l|c|c|c|}
\hline HPI do not GC CTL & 2.923 & $0.0886^{*}$ & COSTL $\downarrow$ HPI \\
CTL do not GC HPI & 0.048 & 0.8274 & \\
\hline HPI do not GC ECI & 5.333 & $0.0015^{*}$ & HPI $\rightarrow$ ECl \\
ECI do not GC HPI & 1.782 & 0.1517 & \\
\hline HPI do not GC UE & 1.031 & 0.4219 & UET $\uparrow$ HPI \\
UE do not GC HPI & 0.645 & 0.7882 & \\
\hline & *significant at p-val.<0.01 \\
\hline
\end{tabular}

It can be seen that HPI over years (Figure 1) has an increasing trend and is not stationary. To handle this, the log-returns of the HPI series is taken and its graph, autocorrelation function (ACF) plot (Figure 2) and summary statistics together with monthly interest rate $(r)$ are presented (Table 5$)$. We see that the average monthly log-return of $\mathrm{HPI}(0.8 \%)$ is lower than average interest rate $(9.6 \%)$ for the same period, in contrast to its volatility against interest rate $(0.48 \%<3.83 \%)$. Even though the return in housing investment less than the bank account, consumers prefer purchasing houses. At this point, to make a neutral interpretation, one should also consider the rental benefit since the buyer will not be paying rent anymore when they own a house. Contrary to the interest rate, the HPI log-return is right-skewed. Anderson-Darling (AD) and Shapiro-Wilk normality tests confirm that HPI logreturn series do not follow normal distribution.

Table 5: Descriptive of Log-Returns and Interest Rates

\begin{tabular}{lllllll}
\hline & Mean & Max & Min & Std.De & Skewness & Kurtosis \\
\hline $\mathrm{HPI}$ & 0.008 & 0.0172 & -0.011 & 0.0048 & -0.955 & 5.1704 \\
$r$ & 0.097 & 0.2285 & 0.0526 & 0.0383 & 2.0871 & 6.8356 \\
\hline
\end{tabular}

Both the ADF and Phillips-Perron (PP) tests indicate that that the log-return series of HPI is stationary $(p<0.01)$. The figure of logreturn illustrates (Figure 3-top) that the return variability on housing market is increased recent years. Further, the housing market have negative returns in recent years. The single significant spike in the ACF strongly suggests that the AR part should be of order 1.

Figure 2: HPI Log-Returns, ACF and PACF Plot

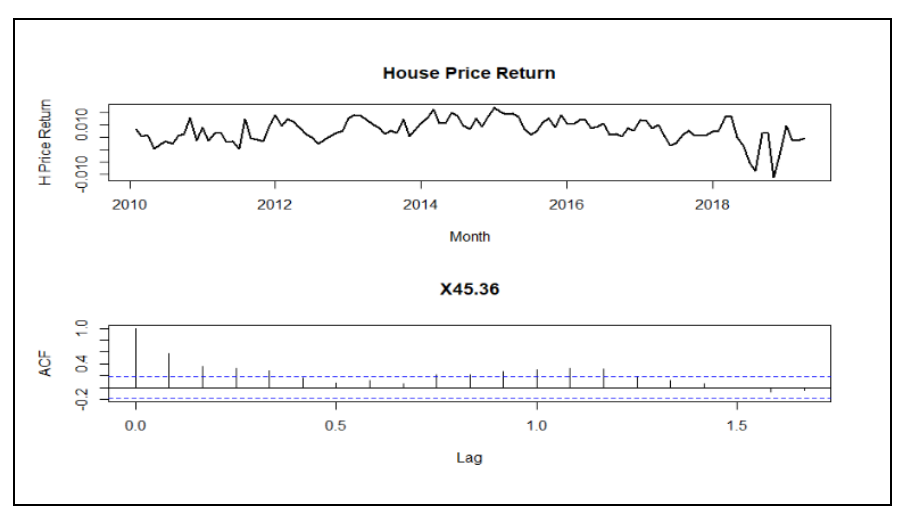

Decomposition to an additive time series model (Figure 3) illustrates top to bottom the actual plot, the overall upward and downward movement, seasonality or monthly pattern, and unexplainable part of the house price log-return series. We see that the log-return series has seasonality which is tested using the WO-test (Webel and Ollech, 2018). The WO-test supports the existence of seasonality.

In our data analyses, we consider the $\operatorname{ARIMA}(p, d, q)$ model without and with seasonality component to have a solid base to make comparison with other models (linear GLM, taken into account). Second, we introduce a seasonal ARIMA and an exponential smoothing model that considers the seasonality in the HPI log-return series. Then, we compare the models with respect to their efficiency indicators, MAPE and MAE. Our analyses are performed using R-software. 
Figure 3: The Decomposed Monthly Return Series

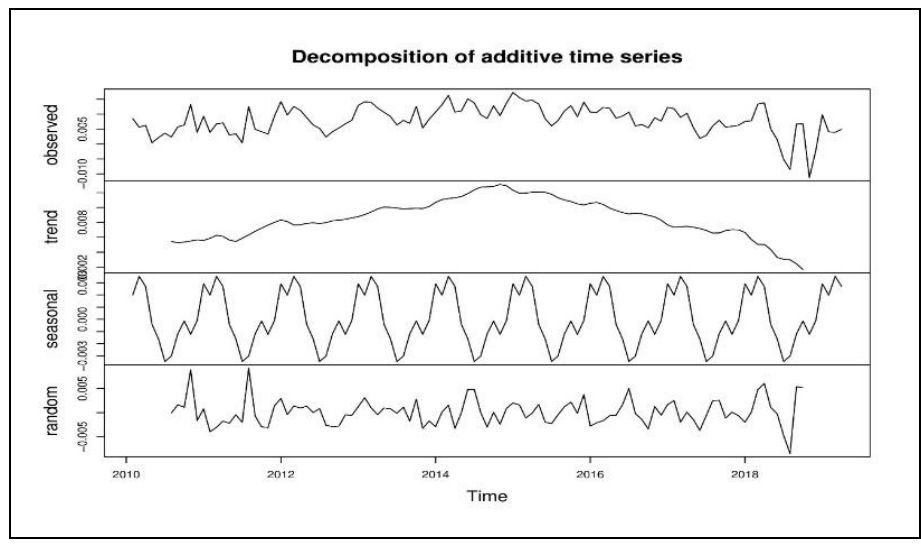

\section{EMPIRICAL FINDINGS AND COMPARISONS}

\subsection{GLM Models}

Due to its flexibility on normality and linearity assumptions, we construct two GLM models having linear (L-Model) and quadratic terms (Q-Model). At this point it is worth to mention that in this setting we use the stepwise method to eliminate un-significant variables. The outputs presented in Table 6 show that for both models GOLD and USD have influence on house prices, whereas the other variables are not significant. The L-Model shows that under ceteris paribus assumptions, the increase in both GOLD and USD will cause an increase in house prices in Turkey's housing market ( $F$-stat. $=33.1, p$-value $<0.0001, R 2=0.36916)$. On the other hand, a power increase such as, a quadratic increase in GOLD has dominant power on increase in the prices (F-stat. = 26.7, $\mathrm{p}$-val. $\left.<0.0001, R^{\wedge} 2=0.4171\right)$. It is also noticed that the explanatory power $\left(R^{\wedge} 2\right)$ of $Q$-model is significantly better than $L$-model.

Table 6: The GLM model estimations

\begin{tabular}{lllll}
\hline L-Model & Estimate & SE & t-stat & p-value \\
\hline Intercept & 0.0005 & 0.0003 & 1.6098 & 0.11024 \\
\hline GOLD & 0.0897 & 0.0204 & 4.3968 & $2.49 E-05$ \\
\hline USD & 0.0898 & 0.0299 & 2.9959 & 0.00336 \\
\hline Q-Model & Estimate & SE & t-stat & p-value \\
\hline Intercept & 0.0001 & 0.0003 & 0.3302 & 0.74184 \\
\hline GOLD & 0.0802 & 0.0199 & 4.0223 & 0.00011 \\
\hline USD & 0.0749 & 0.0294 & 2.5505 & 0.01211 \\
\hline GOLD^2 & 1.4604 & 0.4811 & 3.0356 & 0.00299 \\
\hline
\end{tabular}




\section{2. $\operatorname{VAR}(p)$ Model}

To detect the order of VAR $(p)$ model, we employ information criteria such as AIC, HQ, SC and FPE. All these four criteria suggest that the order of VAR to explain HPI in terms of its own lags and the other explanatory variables and their lags is $p=1$. GOLD, USD, EURO, INF are the variables, which interact with also their first order lags (I1) to HPI. The estimates of the coefficients are summarized in Table 7.

Table 7: Parameter Estimates of VAR(1) for HPI

\begin{tabular}{lllll}
\hline HPI & Estimate & Std.Er & t-stat & p-val \\
\hline Constant & 0.0009 & 0.004 & 2.39 & $0.02^{*}$ \\
\hline HPI.I1 & 0.6394 & 0.080 & 7.96 & $1.8 \mathrm{E}-12^{*}$ \\
\hline GOLD.I1 & 0.0127 & 0.011 & 1.103 & 0.27 \\
\hline USD.I1 & -0.031 & 0.020 & -1.58 & 0.12 \\
\hline EURO.I1 & 0.0228 & 0.020 & 1.124 & 0.26 \\
\hline INF.I1 & 0.1128 & 0.041 & 2.739 & $0.01^{*}$ \\
\hline${ }^{*}$ p.val< 0.01; F-stat=13.96 p-val<0.0001; $R^{\wedge} 2=0.3904$
\end{tabular}

Here, it should be noticed that $\operatorname{VAR}(1)$ considers the other equations estimated in coefficient matrix, A. The models for all explanatory variables based on this approach are presented in Table 11 given in Appendix 1.

\subsection{ARIMA Models}

First, we neglect the seasonality effect for a moment and attempt to construct an $\operatorname{ARIMA}(p, q)$ model for HPI. The best selected model is chosen among many other alternatives whose Bayesian or Schwarz Information Criteria (BIC and SIC, resp.) are the smallest (Table 12 given in Appendix 2). Based on these, we choose $A R M A(1,1)(B I C=-897.4912)$ which is also supported by LjungBox test ( $p$-val. $=0.1678)$. The estimated model is with a significant drift; however, MA coefficient is found to be irrelevant in the model (Table 8).

Table 8: $\operatorname{ARMA}(1,1)$ Coefficient Estimates

\begin{tabular}{llll}
\hline & AR(1) & MA(1) & Intercept \\
\hline Coefficient & 0.6560 & -0.1172 & 0.0079 \\
Std. Error & 0.1684 & 0.2494 & 0.0009 \\
z value & 3.8947 & -0.4700 & 8.4240 \\
p value & $<0.001$ & 0.6383 & $<0.001$ \\
\hline R2 $=0.69345$ & & \\
\hline
\end{tabular}

For this reason, we improve the accuracy by incorporating the seasonality component of HPI. The plausible seasonal ARIMA models for HPI are estimated and listed in Table 13 (Appendix 3). The smallest AIC proposes that $A R I M A(1,1,3)(0,0,2)_{12}$ is the best fitting one yielding significant coefficients ( $p$-val.<0.01) (Table 9).

Table 9: $\operatorname{ARIMA}(1,1,3)(0,0,2){ }_{12}$ Parameter Estimates

\begin{tabular}{lllllll}
\hline & $\mathrm{AR}(1)$ & $\mathrm{MA}(1)$ & $\mathrm{MA}(2)$ & $\mathrm{MA}(3)$ & $\mathrm{SMA}(1)$ & $\mathrm{SMA}(2)$ \\
\hline Coef. & -0.86 & 0.392 & -0.842 & -0.255 & 0.187 & 0.418 \\
\hline Std. & 0.091 & 0.141 & 0.052 & 0.119 & 0.113 & 0.151 \\
\hline z-val. & -9.39 & 2.776 & -14.64 & -2.139 & 1.653 & 2.768 \\
\hline p-val & $0^{*}$ & $0.005^{*}$ & $0^{*}$ & $\begin{array}{l}0.032 \\
\text { 4* }\end{array}$ & $0.0982^{*}$ & $0.0056^{*}$ \\
& & & & & \\
\hline
\end{tabular}

R2=0.76753; *Significant at $0.01 \%$

The lag structure of both $A R M A(1,1)$ and $\operatorname{ARIMA}(1,1,3)(0,0,2)_{12}$ implies that the cyclical effects of Turkey's housing market produced from the past information are transferred endogenously to current house prices through its lagged variables. The errorcorrection terms represent the random fluctuations that lead to cover the fundamental movements of the housing market. 
In case of exponential smoothing method, Holt-Winter model estimates the smoothing parameters as $\alpha=0.034, \beta=0.295$, and $\gamma=0.385$. Such parameter values are determined by minimizing one-step-ahead MSE.

\subsection{Efficiency of the Models}

Even though including more explanatory variables to explain the change in HPI, the GLM and VAR(1) models yield smaller coefficient of determination $\left(R^{\wedge} 2\right)$ compared to the ones obtained using time series models. Also, note that since GLM and VAR models contain more than one explanatory variable, their forecasting power will decrease dramatically due to forecasting errors related to the independent variables. Therefore, we present forecasts for the time series models. To measure the fitting and forecasting performance of the time series models, we separate HPI series into two components and apply in-sample modelling. We consider the first 102 points as training period (train) and consider the remaining 12 points as validation period (test). To detect the performance, mean square error (MSE), root means square error (RMSE) and mean absolute error (MAE) are calculated. Table 10 reveals that in the training part, all three error measures are the smallest in Holt-Winter model compared to $A R M A(1,1)$ and $A R I M A(1,1,3)(0,0,2)_{12}$. On the other hand, in the validation period, $A R I M A(1,1,3)(0,0,2)_{12}$ is superior to both $A R M A(1,1)$ and Holt-winter models according to all three error measures (See Table 10).

Table 10: Performance Measures of the Models

\begin{tabular}{ccccccc}
\hline \multicolumn{2}{c}{$\boldsymbol{A R \boldsymbol { M }} \boldsymbol{A}(\mathbf{1}, \mathbf{1})$} & \multicolumn{2}{c}{$\boldsymbol{A R I M A}(\mathbf{1}, \mathbf{1}, \mathbf{3})(\mathbf{0 , 0}, \mathbf{2}) \mathbf{1 2}$} & \multicolumn{2}{c}{ Holt-Winter } \\
\hline & Train & Test & Train & Test & Train & Test \\
\hline MSE & $2 \mathrm{E}-05$ & $4 \mathrm{E}-05$ & $2 \mathrm{E}-05$ & $\mathbf{2 E}-\mathbf{0 5}$ & $\mathbf{1 E}-\mathbf{0 5}$ & $4 \mathrm{E}-05$ \\
\hline RMSE & 0.005 & 0.006 & 0.0054 & $\mathbf{2 E}-\mathbf{0 5}$ & $\mathbf{0 . 0 0 4}$ & 0.007 \\
\hline MAE & 0.004 & 0.006 & 0.0049 & $\mathbf{0 . 0 0 3}$ & $\mathbf{0 . 0 0 3}$ & 0.006 \\
\hline
\end{tabular}

\subsection{Forecasting}

Forecasts for the following twelve months are plotted along with their $80 \%$ and $95 \%$ confidence intervals in Figures $4 a-c$ for the time series models that fits best to the log-return series, respectively. In these figures, while the black lines represent the observed HPI log-returns, the red dashed lines represent estimated HPI log-returns from the models. More importantly, the blue lines represent forecasting results whereas the shadowed bands correspond to the confidence intervals.

Figure 4a shows that even though $A R M A(1,1)$ is not failing the Ljung-Box test, it's forecasting power is not sufficient enough since it fails to catch the seasonality in the forecasting period. With this model, the forecasted price series appear to be a smooth line for the following twelve months. On the other hand, $\operatorname{ARIMA}(1,1,3)(0,0,2)_{12}$ (Figure $4 \mathrm{~b}$ ) and Holt-Winters exponential smoothing (Figure 4c) captures the seasonality. However, the wide and rapidly increasing prediction intervals in figures show that the housing index log-return can start increasing or decreasing at any time while the point forecasts trend downwards, the prediction intervals allow for the data to trend upwards during the forecast period. However, if we forecast further out into the future, the forecast results become less confident as it is reflected by the confidence intervals generated by the model that grow larger as we move further out through the future. 
Figure 4: HPI 12-Month Log-Return Forecasts with Proposed Models

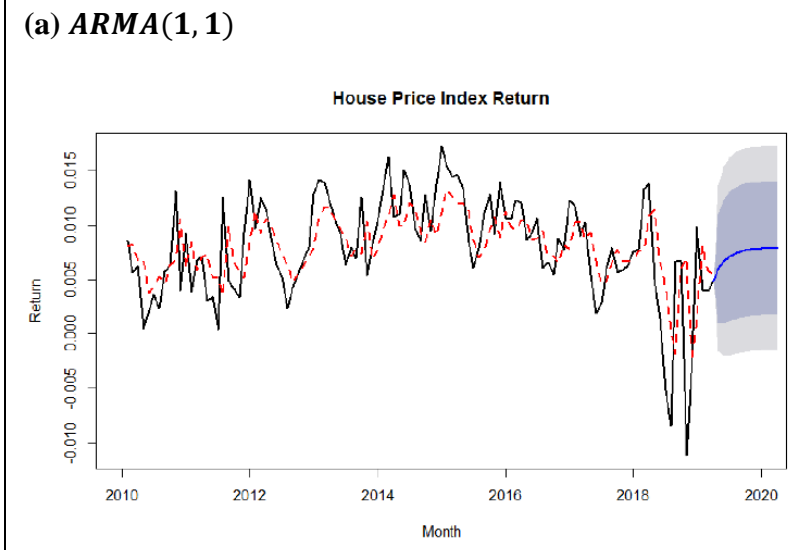

(b) $\operatorname{ARIMA}(1,1,3)(0,0,2)_{12}$

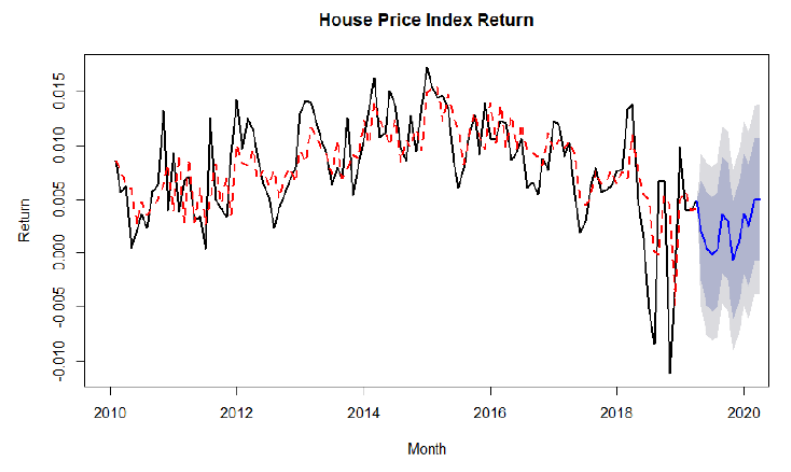

(c) Holt-Winters

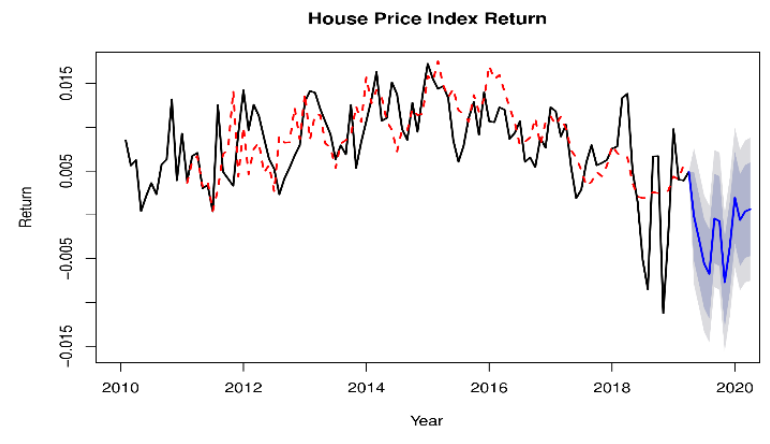




\section{CONCLUSION}

Univariate time series have been widely applied in most areas of finance and economy to obtain better forecasts. Housing markets, however, have rarely been modelled due to the relatively illiquid nature of housing as compared to financial markets.

The technical analysis introduced in this study aims to estimate future house prices and provides sufficient evidence in support of the adequacy of the estimated models for Turkey's housing market. We estimate and forecast Turkey's house price evaluation by using well-known models in the literature, some of which firstly applied to Turkish HPI data set. GLM, multivariate (VAR) and univariate time series models and exponential smoothing approaches are employed on Turkey's house price log-return series. Among six proposed modes, GLM and VAR contains more than one explanatory variables. However, their explanatory power is relatively small. The forecasting power of these models are relatively highly depending on the forecasts of the explanatory variables. In this respect, even though they can be used to determine the house price drivers and for house price prediction, they are not the best candidates for forecasting purposes.

Considering all plausible candidates, the actual number of models considered within the study is diverse and many-fold. Among 25 ARMA and 43 seasonal ARIMA models and Holt-Winter's exponential smoothing model, suggested models with performance accuracy can be used for forecasting Turkey's housing market price evolution. Under the same economic conditions, the forecasting results indicate that the return on Turkey's housing market will not increase in the following 12-months. As a matter of fact, the seasonal ARIMA and exponential smoothing models are forecasting some negative returns within the given forecasting period which should be considered as a warning for Turkey's housing market for the future. On the other hand, GLM and VAR models illustrate that along with the selected well-known explanatory variables, Turkish markets show dependence highly on gold, inflation and foreign exchange rate compared to other important economic indicators contrary to developed markets, such as USA which is highly dominated by mortgage rate (Yilmaz, 2019; Yilmaz and Selcuk-Kestel, 2019).

\section{REFERENCES}

Box, G., \& Jenkins, G. (1976). Time series analysis: Forecasting and control. Holden-Day.

Box, G., Jenkins, G., \& Reinsel, G. (1994). Time series analysis: Forecasting and control. Prentice Hall.

Box, G., \& Jenkins, G. (1970). Time series analysis: Forecasting and control. Holden-Day.

Brown, R. (1959). Statistical forecasting for inventory control. McGraw-Hill.

Chin, L., \& Fan, G.Z. (2005). Autoregressive analysis of Singapore's private residential prices. Property Management, 23(4), $257-270$.

Crawfor, G. W., \& Frantantoni, M. C. (2003). Assessing the forecasting performance of regime-switching, ARIMA and GARCH models of house prices. Real Estate Economics, 31(2), 223-243.

Gatzlaff, D. H., \& Tirtiroglu, D. (1995). Real estate market efficiency: Issues and evidence. Journal of Real Estate Literature, 3(2), 157-189.

Dombaycı, Ö. A. (2010). The prediction of heating energy consumption in a model house by using artificial neural networks in Denizli-Turkey. Advances in Engineering Software, 41(2), 141-147.

Gao, A., Lin, Z., \& Na, C.F. (2009). Housing market dynamics: Evidence of mean reversion and downward rigidity. Journal of Housing Economics, $18(3), 256-266$.

Gardner, Jr., E.S. (2006). Exponential smoothing: The state of the art-Part II. International Journal of Forecasting, 22(4), 637-666.

Gardner, Jr., E.S. (1985). Exponential smoothing: The state of the art. Journal of Forecasting, 4(1), 1-28.

Guirguis, H.S., Giannikos, C.I., \& Anderson, R.I. (2005). The US housing market: Asset pricing forecasts using time varying coefficients. The Journal of Real Estate Finance and Economics, 30(1), 33-53.

Hepşen, A., \& Vatansever, M. (2011). Forecasting future trends in Dubai housing market by using Box-Jenkins autoregressive integrated moving average. International Journal of Housing Markets and Analysis, 4(3), 210-223.

Holden, K., Peel, D. A., \& Thompson, J. L. (1990). Economic forecasting: An introduction. Cambridge University Press.

Holt, C.C. (2004). Forecasting seasonal and trends by exponentially weighted moving averages. International Journal of Forecasting 20(1), 5-10.

Hui, E. C., \& Yue, S. (2006). Housing price bubbles in Hong Kong, Beijing and Shanghai: A comparative study. The Journal of Real Estate Finance and Economics, 33(4), 299-327. 
Hyndman, R.J., Koehler, A.B., Snyder, R.D., \& Grose, S. (2002). A state space framework for automatic forecasting using exponential smoothing methods. International Journal of Forecasting, 18(3), 439-454.

Mcgough, T., \& Tsolacos, S. (1995). Forecasting commercial rental values using ARIMA models. Journal of Property Valuation and Investment, 13(5), 6-22.

Miles, W. (2008). Boom-bust cycles and the forecasting performance of linear and non-linear models of house prices. The Journal of Real Estate Finance and Economics, 36, 249-264.

Nelder, J. A., \& Wedderburn, R. W. (1972). Generalized linear models. Journal of the Royal Statistical Society: Series A (General), 135(3), 370-384. Ooms, M. (2012). Empirical vector autoregressive modelling. Springer-Verlag Berlin Heidelberg.

Öztürk, N., \& Fitöz, E. (2012). Türkiye'de konut piyasasının belirleyicileri: Ampirik bir uygulama. Uluslararası Yönetim Iktisat ve İ̧letme Dergisi, 5(10), $21-46$.

Rapach, D.E., \& Strauss, J.K. (2009). Differences in housing price forecastability across US states. International Journal of Forecasting, 25(2), 351372.

Selim, H. (2009). Determinants of house prices in Turkey: Hedonic regression versus artificial neural network. Expert Systems with Applications, $36(2), 2843-2852$.

Shumway, R., \& Stoffer, D. (2010). Time Series Analysis and Its Applications: With R Examples (3 ${ }^{\text {rd }}$ edition). Springer.

Stevenson, S. (2007). A comparison of the forecasting ability of ARIMA models. Journal of Property Investment \& Finance, 25(3), 223-240.

Türkiye Cumhuriyeti Merkez Bankası [TCMB] (2019). Residential property price index. Retrieved August 22, 2019 from https://evds2.tcmb.gov.tr/index.php?/evds/serieMarket/collapse 26/5949/DataGroup/english/bie hkfe/

Tse, R. Y. (1997). An application of the ARIMA model to real-estate prices in Hong Kong. Journal of Property Finance, 8(2), $152-163$.

Webel, K., \& Ollech, D. (2018). An overall seasonality test based on recursive feature elimination in conditional random forests. In Proceedings of the 5th International Conference on Time Series and Forecasting (pp. 20-31).

Winters, P.R. (1960). Forecasting sales by exponentially weighted moving averages. Management science, 6(3), 324-342.

Yayar, R., \& Karaca, S.S. (2014). Determining factors effecting housing prices with hedonic model: A case of TR83 region. Ege Academic Review, 14(4), 509-518.

Yayar, R., \& Gül, D. (2014). Mersin kent merkezinde konut piyasası fiyatlarının hedonic tahmini. Anadolu Üniversitesi Sosyal Bilimler Dergisi, 14(3), 87-99.

Yilmaz, B. (2019). Housing Market Dynamics and Advances in Mortgages: Option Based Modeling and Hedging [Unpublished doctoral dissertation]. Middle East Technical University.

Yilmaz, B., \& Selcuk-Kestel, A. S. (2019). Computation of hedging coefficients for mortgage default and prepayment options: Malliavin calculus approach. The Journal of Real Estate Finance and Economics, 59(4), 673-697. 
APPENDIX 1

Table 11: VAR (1) estimates for GOLD, USD, EURO, INF

\begin{tabular}{|c|c|c|c|c|}
\hline GOLD & Estimate & Std. & t-value & p-value \\
\hline Intercept & 0.013 & 0.004 & 3.284 & $0.0014^{*}$ \\
\hline $\mathrm{HPI} . \mathrm{I1}$ & -1.280 & 0.851 & -1.504 & 0.1354 \\
\hline GOLD.I1 & 0.036 & 0.122 & 0.295 & 0.7685 \\
\hline USD.I1 & 0.169 & 0.211 & 0.805 & 0.4226 \\
\hline EURO.I1 & 0.070 & 0.215 & 0.328 & 0.7435 \\
\hline Inflation.I1 & -1.020 & 0.436 & -2.340 & $0.0211^{*}$ \\
\hline \multicolumn{5}{|c|}{${ }^{*} p$-val. $<0.001 ;$ F-stat. $=2.2048 p$-val. $<0.0001 ; R 2=0.0934$} \\
\hline USD & Estimate & Std. & t-value & p-value \\
\hline Intercept & 0.005725 & 0.003063 & 1.869 & 0.0643 \\
\hline HPI.I1 & 0.260977 & 0.672620 & 0.388 & 0.6987 \\
\hline GOLD.I1 & -0.099561 & 0.096123 & -1.036 & 0.3026 \\
\hline USD.I1 & 0.534053 & 0.166342 & 3.211 & $0.0017^{*}$ \\
\hline EURO.I1 & -0.018848 & 0.169597 & -0.111 & 0.9117 \\
\hline Inflation.I1 & -1.081128 & 0.344504 & -3.138 & $0.0021^{*}$ \\
\hline \multicolumn{5}{|c|}{ *p-val.<0.001; F-stat. $=5.388$ p-val. $<0.0001 ;$ R2=0.1982 } \\
\hline EURO & Estimate & Std. & t-value & p-value \\
\hline Intercept & 0.0076 & 0.0029 & 2.571 & $0.0114^{*}$ \\
\hline HPI.I1 & -0.225 & 0.6482 & -0.347 & 0.7294 \\
\hline GOLD.I1 & -0.149 & 0.0926 & -1.607 & 0.1110 \\
\hline USD.I1 & 0.318 & 0.1603 & 1.985 & $0.0496 *$ \\
\hline EURO.I1 & 0.258 & 0.1634 & 1.575 & 0.1180 \\
\hline Inflation.I1 & -1.300 & 0.3320 & -3.917 & $0.0001^{*}$ \\
\hline \multicolumn{5}{|c|}{${ }^{*} p$-val. $<0.001 ;$ F-stat. $=6.097 p$-val. $<0.0001 ; R 2=0.2186$} \\
\hline INFLATION & Estimate & Std. & t-value & p-value \\
\hline Intercept & 0.003 & 0.0008 & 4.060 & $9.25 \mathrm{E}-05^{*}$ \\
\hline HPI.I1 & -0.202 & 0.1731 & -1.164 & 0.247 \\
\hline GOLD.I1 & -0.002 & 0.0247 & -0.082 & 0.934 \\
\hline USD.I1 & 0.066 & 0.0428 & 1.542 & 0.126 \\
\hline EURO.I1 & 0.067 & 0.0437 & 1.527 & 0.130 \\
\hline Inflation.I1 & 0.072 & 0.0887 & 0.808 & 0.421 \\
\hline
\end{tabular}

\section{APPENDIX 2}

Table 12: SIC values of ARMA(p,q) models

\begin{tabular}{|c|c|c|c|c|c|}
\hline AR\MA & $\mathbf{1}$ & $\mathbf{2}$ & $\mathbf{3}$ & $\mathbf{4}$ & $\mathbf{5}$ \\
\hline 1 & -897.49 & -896.73 & -891.38 & -888.03 & -891.32 \\
\hline 2 & -896.90 & -894.38 & -890.70 & -883.48 & -887.12 \\
\hline 3 & -891.61 & -891.59 & -887.44 & -883.27 & -886.66 \\
\hline 4 & -886.86 & -883.33 & -882.97 & -879.70 & -876.81 \\
\hline 5 & -882.71 & -888.06 & -879.73 & -878.5 & -873.43 \\
\hline
\end{tabular}




\section{APPENDIX 3}

Table 13: AIC values of $\operatorname{ARIMA}(p, d, q)(P, D, Q)$ models (*without Drift)

\begin{tabular}{|c|c|c|c|c|c|}
\hline$(p, d, q) \backslash(P, D, Q)$ & $(1,0,1)$ & $(1,0,0)$ & $(0,0,1)$ & $(0,0,2)$ & $(1,0,2)$ \\
\hline $0,1,1$ & $\operatorname{lnf}$ & & -891.63 & -897.49 & $\operatorname{lnf}$ \\
\hline \multirow[t]{2}{*}{$0,1,2$} & & & & -908.09 & \\
\hline & & & & $-909.89 *$ & \\
\hline \multirow[b]{2}{*}{$0,1,3$} & & & & -906.30 & \\
\hline & & & & -908.10 & \\
\hline \multirow[b]{2}{*}{$(0,1,4)$} & & & & -904.33 & \\
\hline & & & & $-906.12^{*}$ & \\
\hline$(1,1,0)$ & & -880.3 & & -881.61 & \\
\hline$(1,1,1)$ & $\operatorname{lnf}$ & & -900.84 & -905.16 & -903.74 \\
\hline \multirow[b]{2}{*}{$(1,1,2)$} & & & & -906.31 & \\
\hline & & & & $-908.10 *$ & \\
\hline \multirow[b]{2}{*}{$(1,1,3)$} & $\operatorname{lnf}$ & & -898.57 & -909.30 & -903.11 \\
\hline & & & $-900.41^{*}$ & $-911.09 *$ & Inf* \\
\hline \multirow[b]{2}{*}{$(1,1,4)$} & & & & -902.32 & \\
\hline & & & & $-909.09 *$ & \\
\hline$(2,1,0)$ & & & & -895.59 & \\
\hline$(2,1,1)$ & $\operatorname{lnf}$ & & -900.07 & -905.43 & -904.36 \\
\hline \multirow[b]{2}{*}{$(2,1,2)$} & $\operatorname{lnf}$ & & -902.79 & -908.78 & -903.16 \\
\hline & & & & $-910.58 *$ & \\
\hline \multirow[b]{2}{*}{$(2,1,3)$} & & & & -905.72 & \\
\hline & & & & $-907.49 *$ & \\
\hline \multirow[b]{2}{*}{$(2,1,4)$} & & & & Inf & \\
\hline & & & & Inf* & \\
\hline$(3,1,1)$ & & & & -904.81 & \\
\hline$(3,1,2)$ & & & & -907.31 & \\
\hline
\end{tabular}




\section{APPENDIX 4}

To observe the stationary and invertibility of the univariate time series models we show the complex roots of the polynomials lie outside the unit circle. Therefore, for the sake of simplicity, we plot the inverse roots of the selected models instead in Figure 5. As it is observed from these figures, the complex roots of the polynomials lie within the unit circle. The red dot in the left-hand side of both plots corresponds to the root of the auto regressive part polynomials and the red dot in the right-hand side of both plots corresponds to the root of moving average part. At this point we can conclude that both models are stationary and invertible since their complex roots lie in the unit circle.

\section{Figure 5: Inverse Characteristic Roots for ARIMA and SARIMA}

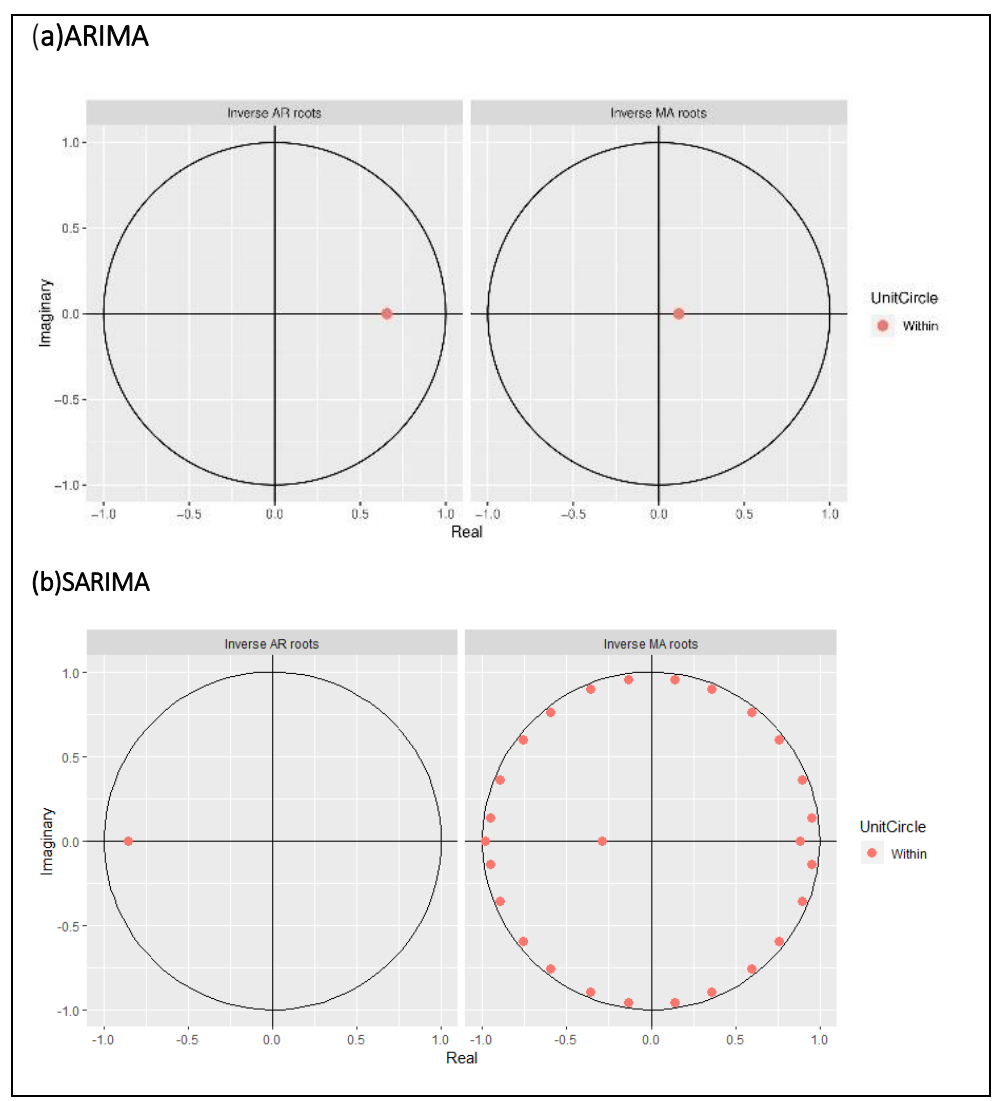

